\title{
New aspects of chromosomal evolution in the gorilla and the orangutan
}

\author{
ANJA WEISE, MADELEINE GROSS, SABINE SCHMIDT, FRANZISKA REICHELT, \\ UWE CLAUSSEN and THOMAS LIEHR
}

Institute of Human Genetics and Anthropology, Jena, Germany

Received September 11, 2006; Accepted October 26, 2006

\begin{abstract}
It is well-accepted that studies of chromosomal changes which have occurred during the evolution of the great apes and the human provide clues towards the phylogeny of these species. Applying recently developed molecular cytogenetic approaches, this study on the chromosomes of the orangutan and the gorilla revealed the presence of cryptic, until now, unrecognized cytogenetic rearrangements mainly within the evolutionary dynamic subcentromeric and subtelomeric regions. On four orangutan chromosomes new rearrangements were detected such as a pericentric inversion in Pongo pygmaeus abeli $\left(\mathrm{PPY}_{\mathrm{a}}\right)$ \#1, complex rearrangements on \#2 of Pongo pygmaeus pygmaeus $\left(\mathrm{PPY}_{\mathrm{p}}\right)$ and $\mathrm{PPY}_{\mathrm{a}}$ and a subtelomeric deletion on $\mathrm{PPY}_{\mathrm{a \& p}}$ \#19. Additionally, the first centromere repositioning in the great apes was detected on PPY ${ }_{\mathrm{a \& p}}$ \#8. Moreover, the breakpoints of four pericentric inversions within the two orangutan subspecies and three pericentric inversions on Gorilla beringei beringei (GBEb) chromosomes \#3, \#11 and \#13 were refined. The new molecular cytogenetic findings are discussed and compared with the available literature.
\end{abstract}

\section{Introduction}

The main benefit of the finished human sequencing project is that it allows a deep insight into the complex structure of the genome. However, a full understanding of its architecture and organization will only be achieved by investigating its recent evolution.

Apart from the well-studied genomes and karyotypes of the human (Homo sapiens; HSA) and his closest relative the chimpanzees, there are two other, less well-characterized branches that belong to the great apes: gorilla (Gorilla spec.;

Correspondence to: Dr Thomas Liehr, Institute of Human Genetics and Anthropology, D-07740 Jena, Germany

E-mail: i8lith@mti.uni-jena.de

Key words: evolutionary breakpoints, Pongo pygmaeus species, Gorilla species, Gorilla beringei beringei, Homo sapiens, multitude multicolor banding, chromosome-specific subtelomere/subcentromere sets, fluorescence in situ hybridization
GGO) and orangutan (Pongo pygmaeus spec.; PPY). Comparative GTG-banding analysis of the human and the great apes discovered well-conserved karyotypes with a few large-scale chromosomal rearrangements among these species (reviewed in 1,2). The advent of molecular cytogenetic techniques using fluorescence in situ hybridization probes (FISH) has considerably enhanced the knowledge of chromosomal evolution in primates (3). Approaches such as FISH-banding methods $(4,5)$ or small locus-specific probes like YACs and BACs (6-12) have made molecular cytogenetics more efficient and accurate in breakpoint mapping.

The following euchromatic differences between the gorilla and human (HSA) karyotypes are well known: pericentric inversions on GGO chromosomes \#1, \#3, \#7, \#8, \#10, \#12, $\# 13$, \#16, \#18 and Y; paracentric inversions on GGO \#1, \#6, $\# 17$ and \#19; a telomeric fusion between GGO \#12 and \#11 leading to HSA \#2; and a translocation between GGO \#4 and $\# 19(2,4)$. Comparing the orangutan (PPY) to HSA, pericentric inversions were described in chromosomes \#2, \#3, \#8, $\# 10$, \#11, \#12, \#13, \#17, \#21 and Y; paracentric inversions for PPY \#7 and \#19; plus a telomeric fusion between PPY $\# 11$ and \#12 (2). In addition, there are reported intraspecies specific differences between Pongo pygmaeus pygmaeus $\left(\mathrm{PPY}_{\mathrm{p}}\right)$ and Pongo pygmaeus abeli (PPY $)_{\mathrm{a}}$ for chromosome 2 (13). However, the gorilla and the orangutan are not in the focus of actual genome sequencing projects, and therefore detailed sequence data are still lacking.

In the present study the karyotypes of Gorilla beringei beringei $(\mathrm{GBEb})$ and $\mathrm{PPY}_{\mathrm{a}}$ and $\mathrm{PPY}_{\mathrm{p}}$ were reinvestigated applying the high resolution multitude multicolor banding (mMCB) (14) and chromosome-specific subtelomere/ subcentromere sets (subCTM) (15). Both techniques, subCTM especially, have the potential to detect cryptic rearrangements within the evolutionary dynamic subtelomere and subcentromere regions as recently reported for the chimpanzee (15). To further refine and obtain additional data on evolutionary conserved, previously known as well as newly detected, breakpoint regions, these were examined in addition by BAC clones.

\section{Materials and methods}

Cells. Molecular cytogenetic studies were performed on peripheral blood lymphocytes of two human probands (Homo sapiens, HSA; one male and one female) in comparison to 
Table I. BAC clones used for the breakpoint mapping of the pericentric inversions on GBEb/PPY chromosome \#12 homologues to HSA $2 \mathrm{p}$.

\begin{tabular}{|c|c|c|c|c|c|}
\hline \multirow[t]{2}{*}{ BAC clones } & \multirow{2}{*}{$\begin{array}{l}\text { Accession code or } \\
\text { end sequence }\end{array}$} & \multirow{2}{*}{$\begin{array}{l}\text { Map/distance from HSA } \\
\text { telomere } 2 \mathrm{p} \text { in } \mathrm{kbp}\end{array}$} & \multicolumn{3}{|c|}{ FISH } \\
\hline & & & HSA & GBEb & $\mathrm{PPY}_{\mathrm{a}} / \mathrm{PPY}_{\mathrm{p}}$ \\
\hline RP11-27N13 & AC104780 & $2 \mathrm{p} 12 / 80500-80-756$ & +++ & +++ & +++ not inverted \\
\hline RP11-4C8 & AC096715 & $2 \mathrm{p} 11.2 / 85660-85815$ & ++ & ++ & ++ not inverted \\
\hline RP11-592A2 & AC068288 & $2 \mathrm{p} 11.2 / 86525-86650$ & +++ & ++ & ++ not inverted \\
\hline RP11-433C18 & AC113612 & 2p11.2/89960-90016 & +++ & ++ split signal & ++ not inverted \\
\hline $\begin{array}{l}\text { RP11-575H3 } \\
\text { centromere }\end{array}$ & $\begin{array}{c}\text { AC018696 } \\
\text { n.a. }\end{array}$ & $\begin{array}{c}\text { 2p11.2/91018-91210 } \\
2 \mathrm{p} 11.1-\mathrm{q} 11.1 / 91800-94700\end{array}$ & ++ & $\begin{array}{l}++ \text { inverted } \\
\text { inverted }\end{array}$ & $\begin{array}{l}+ \text { not inverted } \\
\text { inverted }\end{array}$ \\
\hline RP11-438K19 & AC096670 & $2 q 13 / 111490-111670$ & +++ & +++ inverted & +++ inverted \\
\hline
\end{tabular}

${ }^{a} \mathrm{BAC}$ clones with addresses shown in bold gave split signals indicating the breakpoint spanning region or surround the breakpoint. n.a., not available; +++, very good FISH signal; ++, good FISH signal; +, weak FISH signal; and -, no FISH signal.

Table II. BAC clones used for the breakpoint mapping of the pericentric inversions on GBEb chromosome \#3 homologues to HSA \#4. ${ }^{\text {a }}$

\begin{tabular}{|c|c|c|c|c|}
\hline \multirow[t]{2}{*}{ BAC clones } & \multirow{2}{*}{$\begin{array}{l}\text { Accession code or } \\
\text { end sequence }\end{array}$} & \multirow{2}{*}{$\begin{array}{l}\text { Map/distance from HSA } \\
\text { telomere } 4 \mathrm{p} \text { in } \mathrm{kbp}\end{array}$} & \multicolumn{2}{|c|}{ FISH } \\
\hline & & & HSA & GBEb \\
\hline RP11-793H20 & AC098873 & $4 \mathrm{p} 12 / 48090-48210$ & ++ & ++ not inverted \\
\hline RP11-19F13 & AC105444 & $4 \mathrm{p} 12 / 48711-48737$ & +++ & +++ not inverted \\
\hline RP11-700D1 & AC119752 & $4 \mathrm{p} 12 / 49125-49180$ & +++ & +++ not inverted \\
\hline centromere & n.a. & 4p11-q11/49500-52480 & & inverted \\
\hline RP11-407H18 & AC022267 & $4 q 12 / 46810-57005$ & +++ ch: 4 pter & +++ ch: 3 pter, inverted \\
\hline RP11-2F17 & AC097454 & $4 q 13 / 60750-60915$ & +++ & ++ inverted \\
\hline RP11-498E11 & $\mathrm{AC} 096754$ & $4 q 13 / 65760-65914$ & ++ & ++ inverted \\
\hline
\end{tabular}

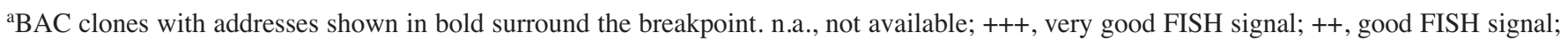
+, weak FISH signal; -, no FISH signal; and ch, cross hybridization.

lymphoblastoid female ape cell lines. The investigated cell lines were kindly provided by Dr M. Rocchi, Bari, Italy (Gorilla beringei beringei, GBEb); Dr S. Pääbo, Leipzig,

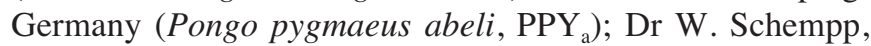
Freiburg, Germany; and Dr H. Hameister, Ulm, Germany (Pongo pygmaeus pygmaeus, $\mathrm{PPY}_{\mathrm{p}}$ ). Chromosome preparations were performed according to standard techniques (16).

Molecular cytogenetics. Ape and human chromosomes were studied in a genome-wide analysis by multitude multicolor banding (mMCB) (14; see Fig. 2). Subcentromere/ subtelomere-specific multicolor FISH (subCTM) was performed in 24 chromosome-specific approaches (Fig. 1). subCTM $(15,17)$ is based on the subcentromeric probes, combined with second generation subtelomeric probes for the short arm and the long arm plus a whole chromosome painting probe. The subCTM-mix for acrocentric chromosomes comprises an acrocentric p-arm-specific probe (midi54, 4) instead of subtelomeric and subcentromeric probes for the short arm.

Refined breakpoint regions of the gorilla and the orangutan were analyzed in more detail by human bacterial artificial chromosome (BAC) clones (Tables I-IV) selected using the NCBI database (http://www.ncbi.nih.gov/mapview/ map_search.cgi?taxid=9606, Build 34.2) and purchased from the Children's Hospital Oakland Research Institute (CHORI), Oakland, CA. DNA was isolated from the BAC clones by standard procedures, PCR-amplified and labeled as described (18). Single- and dual-color fluorescence in situ hybridization (FISH) techniques were performed according to published protocols (19).

\section{Results and Discussion}

FISH strategy. The specific aim of this study was to provide a detailed comparative high resolution molecular cytogenetic survey of gorilla and orangutan karyotypes compared to the human karyotype. High resolution mMCB (14) was used to confirm and refine known evolutionary breakpoints between 
Table III. BAC clones used for the breakpoint mapping of the subtelomeric region and the paracentric inversion on PPY chromosome \#19 homologues to HSA \#17.

\begin{tabular}{|c|c|c|c|c|}
\hline \multirow[t]{2}{*}{ BAC clones } & \multirow{2}{*}{$\begin{array}{l}\text { Accession code or } \\
\text { end sequence }\end{array}$} & \multirow{2}{*}{$\begin{array}{l}\text { Map/distance from HSA } \\
\text { telomere } 17 \mathrm{p} \text { in } \mathrm{kbp}\end{array}$} & \multicolumn{2}{|r|}{ FISH } \\
\hline & & & HSA & $\mathrm{PPY}_{\mathrm{a}} / \mathrm{PPY}_{\mathrm{p}}$ \\
\hline 2111b1 & n.a. & subtelomere $17 \mathrm{p}$ & +++ & - ch 17p11.2;17q11.2 \\
\hline RP11-61B16 & AQ196275 & $17 \mathrm{p} 13 / 585-740$ & ++ & $+++\operatorname{ch~} 17 \mathrm{p} 11.2 ; 17 \mathrm{q} 11.2$ \\
\hline RP11-216P6 & AC015884 & $17 \mathrm{p} 13 / 705-875$ & +++ & ++ ch 17p11.2;17q11.2 \\
\hline RP13-626C16 & n.a. & $17 \mathrm{p} 13 / 1500-1535$ & +++ & ++ ch $17 \mathrm{p} 11.2 ; 17 \mathrm{q} 11.2$ \\
\hline RP11-294G4 & AQ508306 & $17 q 12 / 30350-30520$ & +++ & +++ not inverted \\
\hline RP11-425G1 & AC029189 & $17 q 21 / 34150-34350$ & +++ & ++ inverted \\
\hline RP11-749I16 & AC068669 & $17 q 21 / 35464-35660$ & ++ & ++ inverted \\
\hline RP11-42M14 & AQ046621 & $17 q 22 / 47970-48135$ & ++ & + inverted \\
\hline RP11-142B17 & AC021455 & $17 q 23 / 54020-54195$ & +++ & ++ inverted \\
\hline RP11-561K8 & AZ254615 & $17 q 23 / 57310-57510$ & ++ & ++ inverted \\
\hline
\end{tabular}

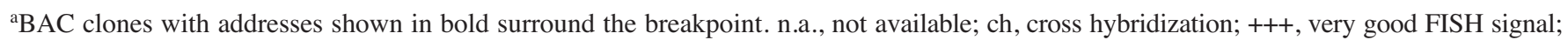
++, good FISH signal; +, weak FISH signal; and -, no FISH signal.

the human (HSA) and the gorilla (GBEb) as well as between the human and both orangutan subspecies $\left(\mathrm{PPY}_{\mathrm{p}} \text { and PPY }\right)_{\mathrm{a}}$. In combination with the chromosome-specific subCTM FISH (15; see Fig. 1A and B), which is able to detect rearrangements in the evolutionary dynamic subtelomeric and subcentromeric regions, these techniques provide the highest molecular cytogenetic resolution for this region today and have the potential to detect overlooked cryptic rearrangements. Similar subtelomeric and/or subcentromeric probes were used previously, however, in a non-systematic way (7,20-22). Additionally, region-specific probes were used to confirm the $\mathrm{mMCB} / \mathrm{subCTM}$ data and whether the obtained results differed from the literature. Larger heterochromatic regions as well as the Y chromosome were not studied here.

Below, the obtained results are listed and each chromosome is discussed according to its order in HSA. The human chromosomes are used as a basis for describing the comparative results and do not necessarily reflect the evolutionary trait that is discussed elsewhere (reviewed in 23). A summary of newly detected and redefined breakpoints/ rearrangements is given in Table IV.

Identification of new rearrangements and refinement of breakpoints in respect to the human karyotype

Chromosome \#1. GBEb and PPY \#1 are homologous to HSA \#1, but they do not have pericentromeric heterochromatin (2). Furthermore, the presence of a cryptic pericentric inversion with breakpoints in $1 \mathrm{p} 11.1$ and $1 \mathrm{q} 21.1$ $(15,22,24)$ could only be confirmed for HSA and not for GBEb and PPY . The subCTM \#1 hybridization pattern of PPY $_{\mathrm{a}}$ differed from that of GBEb and PPY by an extra signal adjacent to the centromere in the long arm of chromosome 1, indicating a cryptic inversion as in HSA \#1. Moreover, both PPY subspecies showed double signals for the pericentromeric sequences (BAC clone RP11-35B4) in the distal region of chromosome $1 \mathrm{p}$ that were absent in the human and gorilla chromosomes (Fig. 1) (22). Additional cross hybridizations were detected within the pericentric region of
PPY chromosome 16; the nature of those remained unclear during this study.

The dynamic nature of the chromosome 1 pericentromeric sequences that are involved in several micro-rearrangements such as deletions, inversions, amplifications and transpositions over short evolutionary times is discussed in more detail in ref. 22.

Chromosome \#2. Human chromosome \#2 evolved by a fusion of two great ape chromosome homologues to GBEb/ PPY chromosomes \#11 and \#12. The fusion point in 2 q13 could be confirmed by mMCB. Several investigations concerning this fusion site were performed on chimpanzee chromosomes (8). Due to this fusion-event the centromere of HSA 2 q homologue chromosome (GBEb/PPY 11) was inactivated.

In addition, GBEb \#12 shows well-known pericentromeric inversion homologues to $2 \mathrm{p} 11.2$ and $2 \mathrm{q} 13(2,4)$. The breakpoint spanning BAC clone is RP11-433C18 (2p11.2) (Table I) and the corresponding breakpoint could be narrowed to a $16.79-\mathrm{Mb}$ region between BAC clone RP11$438 \mathrm{~K} 19$ and the centromere (Table I). These breakpoints are in contrast to a previously proposed one (25). Surprisingly, the BAC clone RP11-433C18 was also breakpoint spanning in a case of a common pericentric inversion in the human. However, the intensities of the splitting signals were slightly different from those obtained in this study, and therefore different breakpoints had to be suggested (26).

The homologues \#12 of both orangutan subspecies also showed a pericentric inversion, but the breakpoint in 2 p11.2 differed from that in the gorilla and was mapped to a $0.59-\mathrm{Mb}$ region between BAC clone RP11-575H3 and the centromere (Table I). The opposite breakpoint was localized between BAC clone RP11-438K19 (inverted in PPY) and the published fusion breakpoint within BAC clone RP11-395L14 (8).

Therefore, it can be expected that the resulting short arm of the orangutan \#12 consists of non-coding, repetitive satellite DNA characteristic for short arms of acrocentric 
Table IV. Summary of new and redefined evolutionary breakpoints/rearrangements for the gorilla and the orangutan in respect to the human karyotype (described by the human ISCN 2005 nomenclature for chromosomes). ${ }^{\mathrm{a}}$

\begin{tabular}{|c|c|c|}
\hline Breakpoints/rearrangements & Gorilla & Orangutan \\
\hline First described by mMCB/subCTM & & $\begin{array}{l}P_{P Y}: \operatorname{inv}(1)(p 11.1 q 21.1) \\
\text { psu } \operatorname{dic}(11)(p 14.2 ; p 11.11-q 11) \\
\operatorname{del}(17)(p t e r)\end{array}$ \\
\hline Redefined by mMCB/subCTM & & 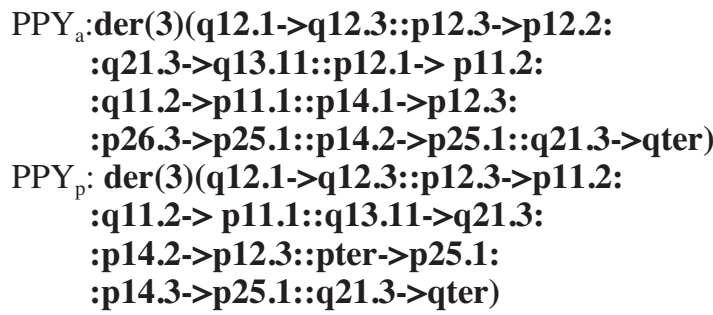 \\
\hline Narrowed down by BACs & $\begin{array}{l}\operatorname{inv}(2)(p 11.2 q 14.1) \\
\operatorname{inv}(4)(\mathbf{p} 12 q 13.3-21.1) \\
\operatorname{inv}(9)(\operatorname{pterq12})\end{array}$ & $\begin{array}{l}\operatorname{inv}(2)(\mathbf{p} 11.2 q 14.1) \\
\operatorname{inv}(4)(\mathbf{p} 12 q 13.3) \\
\operatorname{inv}(9)(\operatorname{pterq12}) \\
\operatorname{inv}(17)(\mathbf{q} 21.1 q 24.2)\end{array}$ \\
\hline Identified by BACs & $\operatorname{inv}(2)(\mathbf{p} 11.2 q 14.1)$ & \\
\hline New information for $\mathrm{n}$ breakpoints & $n=4$ & $\mathrm{n}=28$ \\
\hline
\end{tabular}

aAdresses given in bold indicate new/redefined breakpoints of a rearrangement or a new rearrangement.

chromosomes. This suggestion was already previously confirmed for GBEb (4).

Chromosome \#3. No cytogenetic differences were detected between HSA \#3 and the homologues GBEb \#2 in this and previous studies $(2,4)$, but the homologue chromosomes of both orangutan subspecies showed complex rearrangements compared to HSA and GBEb as well as to each other (13). After evaluation of $\mathrm{mMCB}$ there were a minimum of seven breakpoints in PPY $\# 2$ and 8 breakpoints in $\mathrm{PPY}_{\mathrm{a}} \# 2$ compared to the HSA \#3. We suggest the following description for PPY (ISCN 2005): $\operatorname{der}(3)(\mathrm{q} 12.1->\mathrm{q} 12.3:$ :p12.3->p11.2::q11.2$>$ p11.1::q13.11-> q21.3::p14.2->p12.3::pter->p25.1::p14.3$>$ p25.1::q21.3->qter) and for $P P Y_{a}: \operatorname{der}(3)(q 12.1->q 12.3$ : :p12.3->p12.2::q21.3->q13.11::p12.1->p11.2::q11.2-> p11.1: :p14.1->p12.3::p26.3->p25.1::p14.2->p25.1::q21.3->qter).

For some of these breakpoints detailed mapping data are available (11-20,27-29). Further evidence for more complex repositioning of small intrachromosomal segments was also reported (28).

Chromosome \#4. The homologue chromosomes of the gorilla and orangutan differ through a pericentric inversion from HSA \#4 (2). As the breakpoints of that inversion characterized in this study diverged from the literature $(4,6,30)$, we narrowed down the breakpoints by BAC clones.

For GBEb \#3 the breakpoints were found in a $0.32-\mathrm{Mb}$ region homologous to $4 \mathrm{p} 12$ between BAC clone RP11-700D1 and centromere and to $4 \mathrm{q} 13.3-21.1$ distal to BAC clone RP11-498E11 (Table II). The inversion in PPY \#3 was shorter with the same breakpoint region in $4 \mathrm{p} 12$ but a more proximal corresponding breakpoint as previously reported (30).

Chromosomes \#5/\#6/\#7/\#8/\#10/\#12/\#13/\#14/\#15/\#18/ \#19/\#20/\#21/\#22/\#X. There were no detectable cytogenetic differences to the published literature $(2,4-5,12,27,31-32)$.
Chromosome \#9. PPY \#13 and GBEb \#13 are homologues to HSA \#9 and both show the same pericentromeric inversion resulting in acrocentric ape chromosomes with breakpoints in 9pter and 9q12 according to subCTM and mMCB. The breakpoint in $9 \mathrm{q} 12$ was refined to the region between BAC clone RP11-262H14 and the centromere. As the ape chromosomes lack the HSA-specific heterochromatic block in $9 q 12$, the mapped breakpoint region is closer to the centromere in GBEb and PPY than it is in HSA \#9.

Chromosome \#11. The homologue chromosomes of HSA \#11 are GBEb \#9 and PPY \#8. While the gorilla chromosome \#9 remained unchanged compared to HSA, the orangutan \#8 showed a known pericentric inversion with breakpoints in $11 \mathrm{p} 15.5$ and $11 \mathrm{q} 12.2$ (2).

Applying mMCB and subCTM in this study, the first described centromere repositioning in the great apes was detected (Fig. 4). As shown in Fig. 1D the subcentromeric probes surrounding the centromere in HSA were inverted by the above mentioned inversion but were separated by an active centromere. Instead, a primary constriction resulting in a hybridization gap in mMCB was located in 11p14.2. Centromere repositioning includes simultaneous centromere inactivation and neocentromere formation and contributes to karyotype evolution and speciation. Apart from the human (33) and lower primates (34) centromere repositioning has been reported in Drosophila (35) and plants (36). Nevertheless, the underlying mechanisms are still unclear. Several regions of neocentromere formation were frequently observed in the human and seem to colocalize with evolutionary inactivated centromere sites (29). This centromere repositioning in the orangutan homologue to HSA 11p14.2 was never observed as a neocentromere in the human until now. Considering that the PPY chromosome seems to be the ancestral form (5), a 


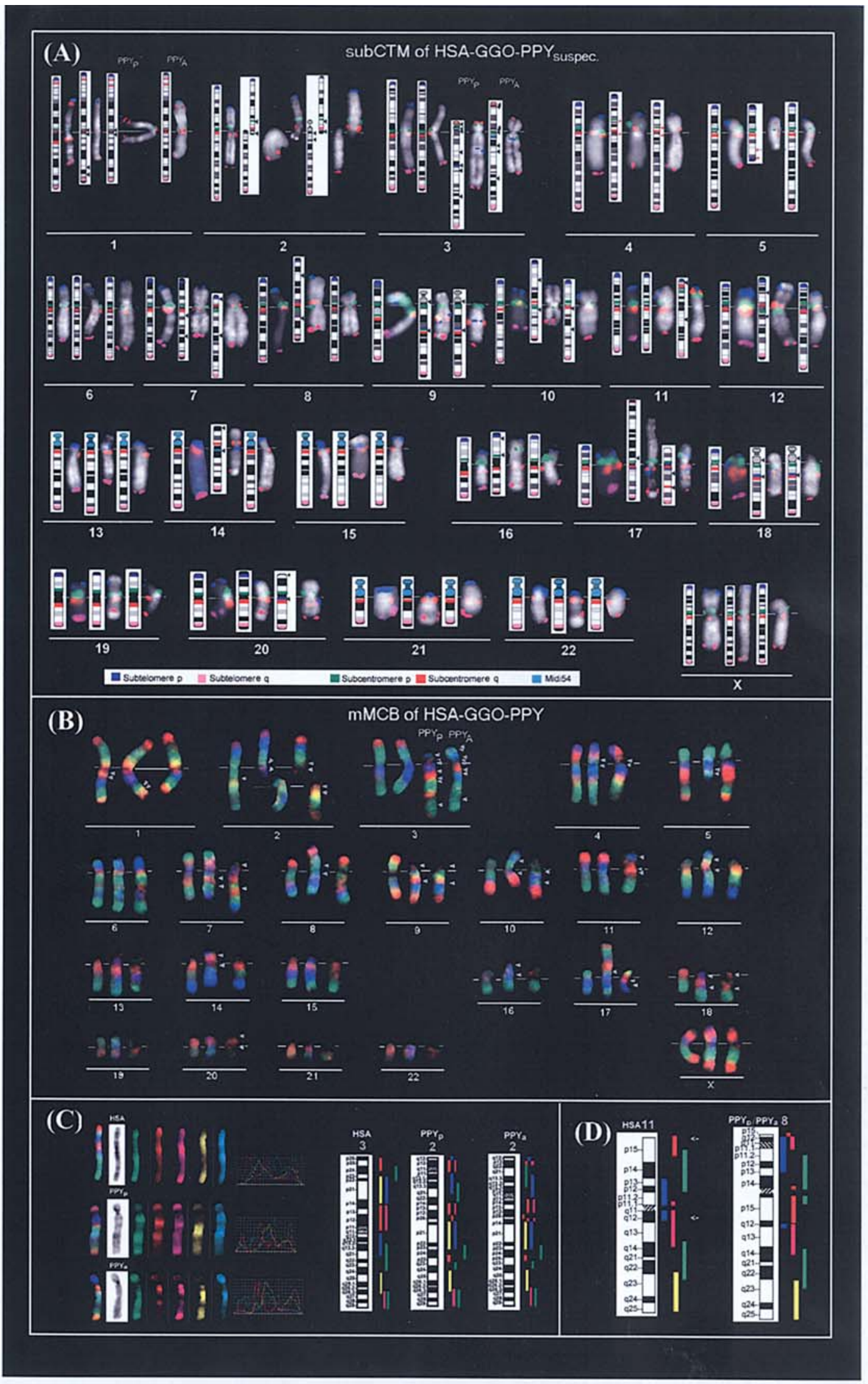

Figure 1. (A) Results of subCTM-FISH probe sets on human (HSA, left), the homologue gorilla (GBEb, middle) and homologue orangutan (PPY ${ }_{\text {subspec }}$, right) chromosomes depicted as ideograms and FISH picture. FISH results have been compiled from 92 different experiments. Chromosomes are ordered according to human chromosome numbers in all karyograms. The color code for subCTM is given at the bottom of A. The Cy5 color channel for the whole chromosome painting probe is not depicted here. Arrows indicate breakpoints compared to HSA. (B) mMCB hybridization example for HSA, GBEb and PPY ${ }_{\text {subspec }}$ comparison in hybridization true colors. Arrows indicate breakpoints compared to HSA. (C) Results from single MCB 3 hybridizations on HAS, PPY ${ }_{\mathrm{p}}$ and PPY $_{\mathrm{a}}$. Left to right: mixed MCB hybridization colors; inverted DAPI; MCB channels in FITC, SpectrumOrange, TexasRed, Cy5 and DEAC; hybridization profiles; ideograms with schematic drawing of MCB results for HSA 3, PPY 2 and PPYa 2. (D) Schematic results of MCB 11 hybridization on HSA 11 and $\mathrm{PPY}_{\mathrm{p}} / \mathrm{PPY}_{\mathrm{a}} 8$. Arrows indicate the known pericentric inversion. Note the centromere repositioning by a changed centromere-fluorochrome background. 
neocentromere formation including the deactivation of the old centromere and a neocentromere formation took place in the gorilla-chimpanzee-human ancestor.

Chromosome \#16. GBEb \#17 and PPY \#18 are homologues to HSA \#16. In contrast to the human \#16 the homologue gorilla chromosomes show a centromere-associated heterochromatic block in $16 \mathrm{p}$ while the homologue orangutan chromosomes have no heterochromatic block. A previously assumed pericentric inversion $(2,37)$ could be confirmed neither by this study nor by other groups (38). Furthermore, a well-known paracentric inversion in 16p13.3 and 16p11.2 could be confirmed on the homologue gorilla chromosome $(2,4)$.

Chromosome \#17. GBEb \#19 is homologous to HSA \#17 and is involved in a translocation with the homologue of HSA \#5 $(2,4,7)$. PPY \#19 which is the homologue of HSA \#17 shows a known paracentric inversion in 17q21.1 and $17 q 24.2(2,9)$. In the present study the breakpoints were refined by BAC mapping to a $3.63-\mathrm{Mb}$ region between $\mathrm{BAC}$ clones RP11-294G4 and RP11-749I16 and distal to BAC clone RP11-561K8 (Table III). Additionally, both PPY subspecies \#19 lacked the subtelomere 17p signal (cosmid 2111a5) (39) and showed diffuse weak signals around the centromere. To verify this terminal deletion and to clarify the suspect pericentromeric cross hybridization signals we applied BAC clones from 17p13. Only the subtelomere probe was completely deleted in the terminal region. Three adjacent BAC clones gave signals in the subtelomeric region plus weak signals within the pericentromeric region (Table III). Actually cross hybridization regions indicate paralogue sequences within the genome that probably gave hints on the segmental duplication processes. Thus, it can be suggested that segmental duplications of the subtelomeric region may have occurred in the orangutan subcentromeric regions of PPY \#19p that compensated a terminal deletion.

Moreover, the subcentromeric probe from HSA $17 \mathrm{q}$ (PAC GS-362K4) (40) gave an additional strong signal in 17q21.3. As there is no evidence of an extra rearrangement besides the previously mentioned paracentric inversion, this may have been caused by segmental duplications as well (Fig. 1A). The dynamic- and duplication-prone nature of this terminal region was also reported (41).

To summarize, we report the identification and/or characterization of evolutionary conserved breakpoints for three gorilla and eight orangutan chromosomes. In other words, we provide evidence for three, until now, undetected rearrangements on orangutan chromosomes as well as hints on complex rearrangements on orangutan chromosome 2 ; in some cases the changes were proven and characterized in detail by additional BAC clone investigations. Furthermore, a centromere repositioning was detected on PPY \#8. Most of the newly described rearrangements were located in the subcentromeric and subtelomeric regions including the centromere repositioning on PPY \#8, a cryptic inversion on $\mathrm{PPY}_{\mathrm{a}} \# 1$, a terminal deletion on PPY \#19 as well as the mentioned complex rearrangements on PPY \#2. Furthermore, the breakpoints for pericentric inversion on PPY \#3, \#12, \#13 and \#19 were narrowed by BAC clones (Table IV). The surprisingly high number of 28 new or refined breakpoints in the orangutan may be due to the fact that these great ape species are not in the focus of science as are the chimpanzees. Therefore, they have not been extensively studied in detail and have not yet been sequenced. The reason that no new cytogenetic rearrangements were discovered in the gorilla can be explained mainly by an entire genome single MCB investigation by Mrasek K et al (4) which was the technical basis of the mMCB approach used in this study. However, pericentric inversion breakpoints on gorilla chromosomes \#3, $\# 12$ and \#13 were refined by BAC clones in the present study.

To conclude, $\mathrm{mMCB}$ and subCTM combined with the application of locus-specific BAC clones provide a more comprehensive look and many new cognitions especially on the orangutan genome. The obtained data provide the necessary basis for a future sequencing project on the gorilla and the orangutan. Moreover, it shows again the necessity for an orthologous numbering system for great ape chromosomes as proposed by McConkey EH (42) as well as a chromosomeband description for a correct karyotype specification.

\section{Acknowledgements}

Supported in parts by the Friedrich-Schiller-Universität Jena grant no. 00469, the Dr Robert Pfleger-Stiftung, the DFG (PO284/6-1), Ernst-Abbe-foundation and the INTAS (2143). Dr M. Rocchi (Bari, Italy); Dr S. Pääbo (Leipzig, Germany); Dr W. Schempp (Freiburg, Germany); and Dr H. Hameister (Ulm, Germany) are kindly acknowledged for providing immortalized ape cell lines.

\section{References}

1. Dutrillaux B: Chromosomal evolution in primates: tentative phylogeny from Microcebus murinus (Prosimian) to man. Hum Genet 48: 251-314, 1979.

2. Yunis JJ and Prakash O: The origin of man: a chromosomal pictorial legacy. Science 215: 1525-1530, 1982.

3. Wienberg J and Stanyon R: Comparative painting of mammalian chromosomes. Curr Opin Genet Dev 7: 784-791, 1997.

4. Mrasek K, Heller A, Rubtsov N, Trifonov V, Starke H, Rocchi M, Claussen U and Liehr T: Reconstruction of the female Gorilla gorilla karyotype using 25-color FISH and multicolor banding (MCB). Cytogenet Cell Genet 93: 242-248, 2001.

5. Müller S and Wienberg J: 'Bar-coding' primate chromosomes: molecular cytogenetic screening for the ancestral hominoid karyotype. Hum Genet 109: 85-94, 2001.

6. Nickerson E and Nelson DL: Molecular definition of pericentric inversion breakpoints occurring during the evolution of humans and chimpanzees. Genomics 50: 368-372, 1998.

7. Stankiewicz P, Park SS, Inoue K and Lupski JR: The evolutionary chromosome translocation $4 ; 19$ in Gorilla gorilla is associated with microduplication of the chromosome fragment syntenic to sequences surrounding the human proximal CMT1A-REP. Genome Res 11: 1205-1210, 2001.

8. Fan Y, Linardopoulou E, Friedman C, Williams E and Trask BJ: Genomic structure and evolution of the ancestral chromosome fusion site in 2q13-2q14.1 and paralogous regions on other human chromosomes. Genome Res 12: 1651-1662, 2002.

9. Sineo L, Romagno D, Guarducci S, Lapini M, Giovannucci-Uzielli ML and Chiarelli B: Chromosome mapping of Miller-Diecker, Smith-Magenis and RARA loci in non-human primates: implications in the evolution of human chromosome 17 . Genetica 114: 275-280, 2002.

10. Yue Y, Grossmann B, Ferguson-Smith MA, Yang F and Haaf T: Comparative cytogenetics of human chromosome 3 q21.3 reveals a hot spot for ectopic recombination in hominoid evolution. Genomics 85: 36-47, 2005.

11. Yue Y, Grossmann B, Tsend-Ayush E, Grutzner F, Ferguson-Smith MA, Yang $\mathrm{F}$ and Haaf T: Genomic structure and paralogous regions of the inversion breakpoint occurring between human chromosome 3 p12.3 and orangutan chromosome 2. Cytogenet Genome Res 108: 98-105, 2005 . 
12. Shimada MK, Kim CG, Kitano T, Ferrell RE, Kohara Y and Saitou N: Nucleotide sequence comparison of a chromosome rearrangement on human chromosome 12 and the corresponding ape chromosomes. Cytogenet Genome Res 108: 83-90, 2005.

13. Seuanez HN, Evans HJ, Martin DE and Fletcher J: An inversion of chromosome 2 that distinguishes between Bornean and Sumatran orangutans. Cytogenet Cell Genet 23: 137-140, 1979.

14. Weise A, Heller A, Starke H, Mrasek K, Kuechler A, Pool-Zobel BL, Claussen U and Liehr T: Multitude multicolor chromosome banding (mMCB) - a comprehensive one-step multicolor FISH banding method. Cytogenet Genome Res 103: 34-39, 2003.

15. Gross M, Starke H, Trifonov V, Claussen U, Liehr T and Weise A: A molecular cytogenetic study of chromosome evolution in chimpanzee. Cytogenet Genome Res 112: 67-75, 2006.

16. Verma RS and Babu A: Human chromosomes - manual of basic techniques. Pergamon Press, New York, 1989.

17. Karst C, Gross M, Haase D, Wedding U, Hoffken K, Liehr T and Mkrtchyan H: Novel cryptic chromosomal rearrangements detected in acute lymphoblastic leukemia detected by application of new multicolor fluorescent in situ hybridization approaches. Int J Oncol 28: 891-897, 2006.

18. Liehr T, Heller A, Starke H, Rubtsov N, Trifonov V, Mrasek K, Weise A, Kuechler A and Claussen U: Microdissection based high resolution multicolor banding for all 24 human chromosomes. Int J Mol Med 9: 335-339, 2002.

19. Liehr T, Thoma K, Kammler K, Gehring C, Ekici A, Bathke KD, Grehl H and Rautenstrauss B: Direct preparation of uncultured EDTA-treated or heparinized: blood for interphase FISH analysis. Appl Cytogenet 21: 185-188, 1995.

20. Eichler EE, Arcidiacono N and Rocchi M: CAGGG repeats and the pericentromeric duplication of the hominoid genome. Genome Res 9: 1048-1058, 1999.

21. Martin CL, Wong A, Gross A, Chung J, Fantes JA and Ledbetter DH: The evolutionary origin of human subtelomeric homologies - or where the ends begin. Am J Hum Genet 70: 972-984, 2002

22. Weise A, Starke H, Mrasek K, Claussen U and Liehr T: New insights into the evolution of chromosome 1. Cytogenet Genome Res 108: 217-222, 2005.

23. Wienberg J: Fluorescence in situ hybridization to chromosomes as a tool to understand human and primate genome evolution. Cytogenet Genome Res 108: 139-160, 2005.

24. Maresco DL, Chang E, Theil KS, Francke U and Anderson CL: The three genes of the human FCGR1 gene family encoding Fc gamma RI flank the centromere of chromosome 1 at $1 \mathrm{p} 12$ and 1q21. Cytogenet Cell Genet 73: 157-163, 1996.

25. de Pontbriand A, Wang XP, Cavaloc Y, Mattei MG and Galibert F: Synteny comparison between apes and human using fine-mapping of the genome. Genomics 80: 395-401, 2002.

26. Schmidt S, Claussen U, Liehr T and Weise A: Evolution versus constitution: Differences in chromosomal inversion. Human Genetics 117: 213-219, 2005.

27. Müller S, Stanyon R, Finelli P, Archidiacono N and Wienberg J: Molecular cytogenetic dissection of human chromosomes 3 and 21 evolution. Proc Natl Acad Sci USA 97: 206-211, 2000.
28. Tsend-Ayush E, Grutzner F, Yue Y, Grossmann B, Hansel U, Sudbrak R and Haaf T: Plasticity of human chromosome 3 during primate evolution. Genomics 83: 193-202, 2004.

29. Ventura M, Weigl S, Carbone L, Cardone MF, Misceo D, Teti M, D'Addabbo P, Wandall A, Bjorck E, de Jong PJ, She X, Eichler EE, Archidiacono N and Rocchi M: Recurrent sites for new centromere seeding. Genome Res 14: 1696-1703, 2004.

30. Marzella R, Viggiano L, Miolla V, Storlazzi CT, Ricco A, Gentile E, Roberto R, Surace C, Fratello A, Mancini M, Archidiacono N and Rocchi M: Molecular cytogenetic resources for chromosome 4 and comparative analysis of phylogenetic chromosome IV in great apes. Genomics 63: 307-313, 2000.

31. Eder V, Ventura M, Ianigro M, Teti M, Rocchi M and Archidiacono N: Chromosome 6 phylogeny in primates and centromere repositioning. Mol Biol Evol 20: 1506-1512, 2003.

32. Misceo D, Cardone MF, Carbone L, D'Addabbo P, de Jong PJ, Rocchi $\mathrm{M}$ and Archidiacono N: Evolutionary history of chromosome 20. Mol Biol Evol 22: 360-366, 2005.

33. Amor DJ, Bentley K, Ryan J, Perry J, Wong L, Slater H and Choo KH: Human centromere repositioning 'in progress'. Proc Natl Acad Sci USA 101: 6542-6547, 2004.

34. Montefalcone G, Tempesta S, Rocchi M and Archidiacono N: Centromere repositioning. Genome Res 9: 1184-1188, 1999.

35. Maggert KA and Karpen GH: The activation of a neocentromere in Drosophila requires proximity to an endogenous centromere. Genetics 158: 1615-1628, 2001.

36. Hiatt EN, Kentner EK and Dawe RK: Independently regulated neocentromere activity of two classes of tandem repeat arrays. Plant Cell 14: 407-420, 2002.

37. Richard F, Lombard M and Dutrillaux B: Phylogenetic origin of human chromosomes 7,16, and 19 and their homologs in placental mammals. Genome Res 10: 644-651, 2000.

38. Misceo D, Ventura M, Eder V, Rocchi M and Archidiacono N: Human chromosome 16 conservation in primates. Chromosome Res 11: 323-326, 2003.

39. National Institute of Health and Institute of Molecular Medicine collaboration: A complete set of human telomeric probes and their clinical application. Nat Genet 14: 86-89, 1996.

40. Knight SJ, Lese CM, Precht KS, Kuc J, Ning Y, Lucas S, Regan R, Brenan M, Nicod A, Lawrie NM, Cardy DL, Nguyen H, Hudson TJ, Riethman HC, Ledbetter DH and Flint J: An optimized set of human telomere clones for studying telomere integrity and architecture. Am J Hum Genet 2: 320-332, 2000.

41. Stankiewicz P, Shaw CJ, Withers M, Inoue K and Lupski JR: Serial segmental duplications during primate evolution result in complex human genome architecture. Genome Res 14: 2209-2220, 2004.

42. McConkey EH: Orthologous numbering of great ape and human chromosomes is essential for comparative genomics. Cytogenet Genome Res 105: 157-158, 2004.

43. ISCN, 2005 - An International System for Human Cytogenetic Nomenclature 1995. Mitelman F (ed). Karger, Basel, 2005. 